NITRO-BLUE TETRAZOLIUM (NBT) TEST IN BACTEREMIC NEONATES. B.D. Chandler, N. Kapoor, B. Barker, R. Boyle and $w$. Oh. Brown Univ. Program in Med. Women $\&$ fants Hosp. of R.I., Dept. of Pediatrics, Providence, R.I. The NBT test is used as supporting evidence for the diagnosis of sepsis in children and adults. In neonates the previously observed high values in normal subjects preclude such use. Our pre liminary observations on 15 healthy term newborns showed that high heparin doses gave falsely elevated NBT values; when heparin dosage was controlled (l unit/ml NBT solution) consistent values of $<20$ were obtained in 68 normal infants of $25-43$ wks of gestation. Since respiratory distress is a comonon presenting sign for both hyaline membrane disease (HMD) and neonatal sepsis, we have performed the NBT test in 25 infants with such signs to evaluate the NBT test in the differential diagnosis of HMD vs. sepsis. Endotoxin-stimulated NBT preparations were also performed to insure phagocytic inducibility of the neutrophils. NBT slides were read without knowledge of each infant's clinical diagnosis. HMD was confirmed by classical chest roengenograms and a negative rapid surfactant test in gastric aspirate, and sepsis by positive blood (4 cases) or CSF (1 case) cultures. The results were as follows:

sults were as follows:
\begin{tabular}{|l|c|c|c|}
\hline & Normals $(n=68)$ & H.M.D. $(n=20)$ & Sepsis $(n=5)$ \\
\hline RNBT (M ISD) & $11.3 \pm 7.5$ & $36.7 \pm 21.8$ & $73.0 \pm 9.3$ \\
\hline P values & $<0.001$ & $<0.001$ &
\end{tabular}

Three additional bacteremic infants had no neutroph1ls on the NBT smears. The NBT test appears to be a reliable indicator of tiation of HMD from bacterial infection.

\section{EVIDENCE THAT ENDORPHIN (s) MODIFY THE RESPIRATORY RESPONSE TO NEONATAL ASPHYXIA. Victor Chernick,} Pediatrics, Deborah L. Madansky, and Edward E. Lawson. Dept. of Endorphins are endogenous polypeptides with activity system and bind to opiate receptors. They presumably function as inhibitory neurotransmitters in pain pathways. We tested the hypothesis that endorphins modified the respiratory response to asphyxia in newborn rabbit pups (3-5 days of age). Pups from the same litter were injected I.P. with either $1 \mathrm{ml}$ saline or $1 \mathrm{ml}$ (0.4mg) naloxone, a specific endorphin antagonist. Five minutes later asphyxia was produced by tracheal occlusion and maintained until gasping resumed after primary apnea. Four occlusions were done on each pup and 3 minutes allowed for recovery between occlusions. The time to primary apnea increased by 20 from $44.2 \pm 1.5$ (S.E.) sec in saline pups to $52.9 \pm 1.9 \mathrm{sec}$ in naloxone pups ( $p<.001$ ) while the duration of primary apnea decreased by $608(45.5 \pm 11.1$ v8 $18.3 \pm 2.0 \mathrm{sec})(p=.01)$. The tracheal pressure achieved during the first gasp following primary apnea was identical in saline and naloxone pups $(54.2 \pm 2.7 \mathrm{vs} 54.3 \pm 2.5 \mathrm{~cm}$ $\mathrm{H}_{2} \mathrm{O}$ ). Naloxone acts by competitive blockadis (if opiate (endorphin) receptors. These data therefore provide evidence that endorphins modify the respiratory respense to asphyxia by decreasing the frequency of respiratory center ilscharge but do not appear to decrease the amplitude of the resplratory center output at the time of the first gasp.

\section{THE NEED FOR FOLLOWUP OF FAMILIES WHO EXPERIENCE A}

963 PERINATAL DEATH. Ronald Clyman, Jane Rowe, Charlotte Green, Cynthia Mikkelsen, Jeannette Haight, Linda Ataide. (Spon. by Roder1c Ph1bbs) Dept. of Pediatrics, University of California, San Francisco.

We conducted a retrospective study by telephone interview (1224 months later) of 26 famflies who had experlenced perinatal death ( 7 st1llborn, 19 neonatal). 14/26 had had subsequent pregnancies. 6/26 had prolonged grief reaction (12-20 months). Those mothers with a surviving twin or subsequent pregnancy $<5$ months following the death were at higher risk for a prolonged grleving pertod than were those without subsequent pregnancy or one $>6$ months later $(p<.01) .12 / 26$ familles obtained information about the cause of death and risk of recurrence only during hospitalization; subsequent contact, weeks to months later, provided additional information in $14 / 26$ (by phone in 5 , in person in 9 ). 22/26 mothers met predetermined criterla for having adequate understanding of cause of death and/or risk of recurrence; 4/26 knew neither. Understanding was significantly related to followup contact by phone or in person. 15/22 with adequate understanding were partially or totally dissatisfled with the information they received or the way they received $1 t$. Familles who received no In person followup contact were more likely to be dissatisfied (p (.05). In summary, the presence of a surviving twin or early subsequent pregnancy may be associated with a prolonged maternal grief reaction following perinatal death. Followup by phone or in person resulted in better understanding of the cause of death and risk of recurrence but only in person followup was associated with satisfaction with the information.
964 INFUENCE OF HEME ON THE KINETICS OF BILIRUBIN BIND-

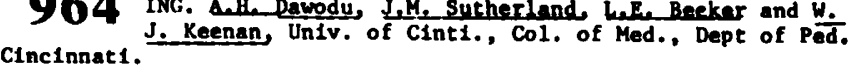
Non-bilirubin products of hemolysis have been suggested to reduce the bilirubin binding capacity of serum albumin. If these products interfere with the albumin binding of bilirubin a child with hemolytic disease would be at higher riok for billrubin encephalopathy at a given level of aerum blitrubin than a child without hemolytic disease. Experiments were conducted to test the hypothesis that heme interferes with the albumin binding of bilirubin. Allquots of pooled cord sera with increasing concentrarubin. Alquots of pooled cord sera with increasing concentrations of heme and unconfugated bilirubin were compared to control ured by enzymatic oxidation. Heme concentrations of greater than $7.5 \mu \mathrm{M}$ resulted in significantly higher levels of unbound bilirubin (paired $t, p<0.001$ ) over a wide range of total bllirubin concentrations. The disenclation constent of the primary binding site for control and hem containing allquots (Hewe-15WM) were $3.9 \times 10^{-8}$ and $8.3 \times 10^{-8}$ respectively. The second clase of bindIng sites appeared to be elullarly affected. As one of the nonblilrubin products of hemolysis, heaw appears to interfare with both the p
bllirubin.

96 DEVELOPMENT OF THE NEWBORN'S SUCKING RESPONSE: RELA-

965 TIONSHIP TO MATERNAL, OBSTETRIC, AND INFANT VARIABLES. Sheryl Ellison, Gene C. Anderson, \& Dharmapuri vidyasagar, Coll. Nrsg., Dept. Pedlat. ALSM Univ. of 111. . Chicago. The sucking response was quant i tatively studled in 13 lowbirth-weight newborns (LBWN) and 17 normal-birth-weight newborns (NBWN). An electronic suckometer measured maximum intensity pressure for suction and expression components of the sucking response for four consecutive 15-second intervals at $5,15,30,45$, and $60 \mathrm{~min}$. of life. At these times L.BW exerted mean suction scores of 5.8 , $8.7,3,1,7.8$, and $9.3 \mathrm{mmHg}$ and mean expression scores of 14.0.11.9, $25.0,34.0,69.2$, and 93.7 NBWN exerted mean suction scores of 2.1 , $5.6,7.3,8.3$, and $7.0 \mathrm{mmHg}$. Vigorous crying in LBWN at $30 \mathrm{~min}$. of life during possibly life-saving treatments (e.g., l.v.'s) and in NBWN at $5 \mathrm{~min}$. of life may explain low suction scores at these times. Positive correlations were found for both LBWN and NBWN between maximum suction score and birth weight $(r=0.62 ; p<.01)$ and maximum suction score and gestational age $(r=0.60 ; p<.01)$ for NBWN between maternal parity and mean suction score at $5 \mathrm{~min}$. ( $r=0.58$; $p<.02$ ) and for LBWN between second stage of labor and mean expregsion score at $5 \mathrm{~min}$. $(r=0.60 ; p<.05)$. No significant differences were found in sucking scores based on race, sex, maternal medication, or the occurrence of prenatal, intrapartal, or neonatal complications. This investigation shows the sucking response is present even in most low-birth-weight infants during the first hour of life. Giving sucking experlence to the transitional newborn may allow earlier safe feed ings. The portable suckometer of-

96 hepatic bilirubin glucuronidation in the human fetus. 966 Bertram P. Pelsher, Jack E. Ma1dman, Nuemi M. Carp10 University of Callfornia, Irvine, School of Medicine; V.A. Hospital, Department of Medicine, Long Beach; Charles Drew Postgraduate Medical School, Department of Obstetr1cs-Gynecology, Los Angeles.

Direct information concerning the fetal development of bilirubin glucuronidation in man has been lacking. Both the activity of the confugating enzyme, bilirubin UDP-glucuronyltransferase (UDPGT) and the ava1lability of the substrate, UDP-glucuronic acid (UDPGA) may affect hepatic bilirubin glucuronidation. Assays of UDPGT and UDP-glucose dehydrogenase (UDPGD) were performed in the livers of dead aborted human fetuses and the results were compared with values obtained in normal adults. Hepatic UDPGT activity (unit $=\mu \mathrm{g}$ bilirubin conjugated/gm 1 iver $/ \mathrm{hr}$ in 2 fetuses, aged 17 and 22 weeks was 140 and 220 units, respectively and in 7 fetuses, aged $11-19$ weeks was less than 100 units (normal adult $=600-2,000$ units). Hepatic UDPGD activity (unit nmoles UDPGA formed $/ 100 \mathrm{gm} 11 \mathrm{ver} / \mathrm{mIn}$.) in 10 fetuses, aged 10-18 weeks, ranged from $7.7-15.0$ un $1 \mathrm{ts}$ (mean $\pm \mathrm{SEM}=11.7 \pm 8.0$ ) and in 8 normal adults ranged from $26.3-49.2$ units (mean \pm SEM $38.1 \pm 3.0) \quad(p<0.001)$. These data show that the in vitro hepatic formation of bilirubin glucuronide and UDPGA is markedly reduced in the human fetus in the first half of gestation compared to normsi adults. The relation of these findings to in vivo hepatic bilirubin metabolism and glucuronide conjugation in general in the human fetus and newborn remains to be determined. 